\title{
MIDDLE EUROPEAN SCIENTIFIC BULLETIN DEVELOPMENT OF COORDINATION ABILITIES OF 5-7 YEAR OLDS IN PRESCHOOL EDUCATION INSTITUTIONS
}

\author{
Rahmonova Dilhumor Fayzullayevna ${ }^{1}$ \\ Jizzakh State Pedagogical Institute Named after Abdulla Qodiriy \\ Student of the Faculty of Preschool Education 1-year master's degree
}

\begin{abstract}
Annotation. The following article discusses innovative ideas in the development of coordination skills of 5-7 year olds in the preschool education system.

Key words: Coordinates, physiology, individual, innovation, folk games, zuv-zuv, white terakmi-blue terak,
\end{abstract} joining, flexibility, national kindergarten model, Innovative kindergartens.

\section{INTRODUCTION}

Today, improving the quality of the preschool education system is a requirement of the time to prepare young children for school. This in turn places more responsibility on preschool education organizations. It is necessary to properly shape the education of the younger generation in preschool education. However, in the upbringing of young people, not enough attention is paid to the development of their coordination skills. In terms of the ability of 5-7 year old children on the threshold of school to develop perfectly in all respects. Scientific results and insights give good results in the development of coordination capacity. Consider the development of physical coordinate ability in children aged 5-7 years.

\section{MAIN PART}

The So let's focus on the physiology of 5-7 year olds. At this age, some children move fast, but most of the rest of the category members move slowly. Gradual adjustment of the abilities of these two categories of children gives very good results. Of course, in considering the application of such methods, we will consider the following cases with a focus on the general physiology of the psychology of young children.

\section{As an example}

Fast-moving: We become slow-moving. Fast-moving children sometimes get tired quickly. Fatigue and malaise can occur in fast-moving children if breathing is not regulated properly.

Slow-moving children: This type of child is sometimes less tired. The reason for the slow movement is mainly the presence of a state of fear in relation to speed in child psychology.

In the above cases, the physiology of children aged 5-7 years is different. In their case, attention should be paid to each child individually. Fear in slow-moving children must be overcome through various games, otherwise weight gain will be observed as a result of inactivity, if the weight gain is not stopped, it will negatively affect the child's mental state and have significant consequences not only for physiology and psychology.

In the development of children's abilities in the above-mentioned system of preschool education, almost no attention is paid to Uzbek folk games, but through folk games, the following situations develop well in children.

Speed

Resistance

Flexibility

Power

Achieving effective action

Folk Games: Consider developing the ability to coordinate through.

In a fast-moving child: White-poplar-blue poplar strengthens the leg muscles in the game by playing the game, and prevents cases of rapid fatigue. In the zuv-zuv game, the partial movement of the children results in the ability to coordinate with each other.

Slow-moving child: Through the game of white-blue poplar-blue poplar, children develop the following conditions well. Fear of moving fast (overcoming through play) and moving fast. The respiratory system of the zucchini game allows oxygen-saturated blood to reach the brain.

Folk games give good results to develop the coordination ability of children aged $5-7$, just need to put it right.

In preschool education, it is crucial to identify and shape any coordination ability of children

A lot of scientific research is going on through folk games. It is recognized that folk games are beneficial for the whole organism of children.

Nervous system

Improving the circulatory system

Leg and arm muscles

Gives a positive result in improving the activity of hormones and various other areas of the body.

The gradual introduction of 5-7-year-old children in pre-school educational institutions to folk games and the introduction of kindergartens will have a very effective effect on the formation and identification of children's coordination skills, will create a new model of innovative national kindergartens. 
Interaction of national and modern methods to develop children's coordination skills through the model of national kindergartens, the use of innovative technologies in the preschool education system in which cartoons highlight the priorities of national design, poems heroes in English songs (in national costumes) expression) is a very effective method.

\section{CONCLUSION}

The national kindergarten model reveals positive traits in child rearing. This method will be a big step in developing coordination skills. The next step is to bring the child a video and games of national and modern robit dance - we would have made a sharp turn. The following situations can have an effect on the development of which ability in a child.

1-muscle flexibility

2- Ability to apply innovative technologies

3 Increases visual sensitivity

4 sharply increases the imagination and the growing interest in national robots and toys, which in turn is very much like reducing the demand for so-called toy types such as western toys (cherapashka, chelavuk povuk).

\section{References}

1. H. N. Azirkhojayev. Pedagogical technology and pedagogical skills.

2. AV Detrovsky, General Psychology" Tashkent teacher 1992.

3. Rasulova M. Abdullayeva K. Safarova L. Basic program of child development and preparation for school-T: UzPFITI 1999.

4. Fazliddin Khaydarov. Nargiza Khalilova. "General Psychology" Tashkent - Innovation Enlightenment - 2019. 